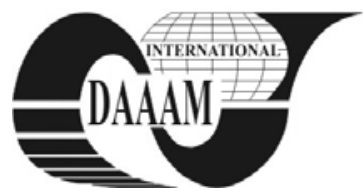

\title{
INVESTIGATION OF RISK MANAGEMENT PROBLEMS WHEN CONSTRUCTING OF THE QMS PROCESSES
}

\author{
MIKHAILOVA, E[katerina]; MIKHAYLOV, M[axim] \& STAZHKOV, S[ergey]
}

\begin{abstract}
Risk management in the organization's Quality management system (QMS) currently represents the greatest challenge that leaders of any organization, regardless of occupation, have to face on a daily basis. This is due to the fact that any organization operating under conditions of uncertainty and seeks to maximize profit in the constantly changing internal and external environment. The paper studies the features of risk management technology in the organization's QMS. The problems of the risk management in Russian companies are identified; the activities for the risk management when implementing of the QMS in processes are offered Key words: management, quality, risks, processes
\end{abstract}

\section{INTRODUCTION}

The entrepreneurial activity is closely linked with the concept of the risk. For a successful existence in a market economy the entrepreneur has to implement technological innovations and to take bold, non-trivial action, and this increases the risk. Therefore necessary to properly assess the risks and be able to manage risk to achieve more effective results in the market. (Cherkasov et. al., 1999)

The introduction of the Quality management system (QMS) could minimize risks and reduce costs, especially, by optimizing the organization's business processes and the development of competent documented descriptions of the order implementation processes.

\section{PROPOSED SOLUTION}

In the period of the development and implementation of the QMS should be paid great attention to selection processes and the documented description to reduce the risks of errors (defects, inconsistencies, inefficient actions) when they are executed. Develop a documented description of the processes to prevent errors in execution of processes to reduce the risks of their occurrence or soften their consequences.

There are two basic concepts: the risk and consequences of the risk. Under the risk can be understood as the possibility of improper performance of some actions within the process, as well as the possibility of inappropriate inputs to the next process.

The main characteristic of risk is the probability of its occurrence. Consequence of risk - is reducing the effectiveness and efficiency of the process due to the implementation of the risk or not execution of the process. The main characteristic is their seriousness. Risks and their consequences are associated causal link (http://www.iso.org, 2009).

The risks include, in particular, the following categories:

- Risk of lack the required resources for the performer;

- Risks of of insufficient qualification of the performer;

- Risks of accidental performer's errors (human factor);

- Risks of lack of sufficient information for the performer;

- Risks of lack of sufficient time for the performer's job;
- Risks of lack of inputs of the process, their non-compliance or untimely receipt;

- Risks lack of coordination of various performers.

For each organization must be developed its own list of risks specific to the organization and field activities. The risk consequences, for an example, could be:

- Output of the process non-fulfilment of specified requirements.

- Output of the process received late (order fulfilment, procurement of raw materials, budget development, filling vacancies, etc.)

- Costs of different types of resources unplanned;

- Excessive load performers of the process (for example, need to work on weekends).

It is helpful to consider the consequences of risk not only for the organization, but also for other interested parties: in the first place - for consumers, it is also possible - for staff, suppliers and society (in particular, it concerns the risks related to occupational safety and impact on the environment).

The basic idea of registration the risks in the development of documented process descriptions is that the description should answer the question: how you can eliminate the significant risks associated with the implementation process, reduce the likelihood of their occurrence or their consequences or, at least, quickly identify their implementation and respond to it. In another case, if the document only describes the situation "when things are going well and there is no problem", the benefits of such a document is minimal. After all, perfomers are most likely to look into this document if they have problems in the implementation of the risk - in order to understand how to act in an irregular situation.

\section{IDENTIFIED PROBLEM}

The idea is very simple at first, but this is the main problem of Russian companies. To obtain ISO 9001 certificat should be developed mandatory documented procedures. The developers of these descriptions are the simplest way: describe the standard pattern of action (the most well-established and clear) and do not allow any of its offshoots, the risks associated with the implementation and the need to respond to them. Such documents can meet the requirements of the standard and pass the certification, but such descriptions will be inoperative and they usually do not give an answer to the more important question: how to reduce the likelihood of negative situations. Such documents are seen as a formality required to obtain a certificate.

Organizations in Russia perceive ISO 9001 as part of the competition, but do not realize that the standard is also a tool to create a bespoke management system and in addition meet the requirements of the standard should be an analysis of the organization, its policies and issues. The analysis of the risks associated with the process can be an effective tool to display a documented description of this process, the specifics of the organization. 


\section{PROCESS DESCRIPTION}

The first step is to compile a list of significant risks and their consequences for each process. The input for this stage should be developed all the processes in the organization and assigned responsibility for each process. List is a crossfunctional team, composed of representatives of all departments involved in the process, and consumers in the process. In the next stage the group, identifying significant risks to the process, must decide if further action:

- Selection of the embodiment of a process that will eliminate or reduce risk.

- Selection of the embodiment of a process that will mitigate the consequences of risk in its implementation.

- Monitoring of risk and rapid response to it, in particular, to mitigate its effects For example, if a significant risk to the process of procurement management is determined violation of the terms of supply of production, the process should include steps to prevent such a situation, such as evaluation of suppliers on this criterion. If risks exist, the first level of decomposition developed by this action. If certain acts of the first order as the significant risks identified, they will be described in more detail at lower levels, etc. Thus it becomes clear what units should be given more attention (for example, give more detailed description of the action). On the other hand, it allows you to see the blocks that do not affect any of the material risks. For them it is possible to consider whether reducing the level of detail of description, which will reduce and simplify the document, as well as - to reduce excessive regulation of the workforce.

This approach provides flexibility to find the optimal level of detail in descriptions of processes. On the one hand, the documents may be very detailed, where their absence could lead to negative consequences - the implementation of significant risks. On the other hand, this approach prevents the excessive detail of the documents where it is needed. But the main thing - every time it is not just about what we need to develop a document that describes how to perform certain actions (without a clear understanding of the purpose of this document), and the need to design and document the procedure for such follow these steps, which will protect the organization from certain risks. The value of the documents it becomes clear how their developers and users.

The third step is to assess and rank risks using different techniques. It may apply the classical techniques of risk management, such as FMEA (failure modes and effects analysis), What-if, FTA (faut tree analysis) (Vasileval, 2010).

The basic idea is the evaluation of each of the risk on several quantitative parameters. First, such parameters are the probability of the risk and seriousness of its consequences, in some cases can be estimated as the probability of detection risk at an early stage (when it is still possible to respond quickly without significant consequences to exit the process). At ISO 9001 there are no requirements for the identification, assessment and risk analysis, however, the quality management system can be described as a combination of methods, techniques and quality management activities, allowing a certain extent, predict the onset of risk events and to take measures to eliminate or reduce the adverse effects of such events. (Dubrov et al., 2000).

In terms of ISO 9001 deviation "fact" from the "plan" - a "non-fulfillment requirements". According to ISO 9001from a comparison of the definition of a risk to the definition of a "potential discrepancy" - is a very similar concepts. Accordingly, any preventive action - an action aimed at reducing risk. "Mismatch" in terms of risk management - is to realize the risk that must be managed.

In this way, the management of corrective and preventive actions, a process during which, in fact, operational risks are managed. The same applies to internal audits. If the purpose of internal audit - to assess how the actual process is carried out in accordance with a given technology, we can identify of realized risk. If you identify with the "potential discrepancy," that is, identify risks, then we can introduce a "preventive action", that is to mitigate risk.The process of "Internal Audit" will be renamed "The identification of operational risks" (http://www.quality.eup.ru, 2011).

\section{EXPECTED RESULTS}

After completing all steps above it will be received a list of all potential risks on the processes and the risks ranked.

The next step is planed to conduct a risk analysis. To do this, is planed to develop a methodology using a mathematical model that will best fit for analysis of the identified risks. As a tool for risk analysis is planned to create a program to automate this process. Proper risk analysis can provide an objective amount of errors and losses and plan ways to prevent or reduce, and in failing to prevent the loss - to ensure their recovery.

Nowadays the most effective is a comprehensive approach to risk analysis. On the one hand, this approach provides a more complete picture of the possible outcome of the implementation process, all positive and negative surprises, but on the other hand, makes possible a wide application of mathematical methods (especially the probabilistic and statistical) for risk analysis (Stupakov et al., 2006).

The final step will be to develop a risk management program of action to reduce the extent and magnitude of the risk. The program is a set of control actions in the form of antirisks activities and necessary for the amounts and sources of funding, specific artists and deadlines. Eventually it is planed to obtain the risk-management system based on the implemented QMS in the organization.

\section{CONCLUSION}

Historically, the most active risk management is applied in the banking and financial spheres. Today the majority of the global business community solidarity that the introduction of a risk management approach - a necessary condition forthe provision of strategic business competitiveness, regardless of scope.

The fact that risk control is necessary for creating a stable, successful and competitive organization, no one in doubt. And one of the tools that enhance the competitiveness of the organization stands its QMS (Vose, 2008). It is necessary to consider organization specific features when implementing technology risk management and use methods to reduce risk and comply with the procedure of its implementation.

\section{REFERENCES}

Dubrov, A.; Lagosha, B. \& Hrustalev, E. (2000). Modeling the risk situations in Economics and Business, Finance and Statistics, Moscow, Russia

Stupakov, V.; Tokarenko G. (2006). Risk-management, Finance and Statistics, Moscow, Russia

Vose D. (2008). Risk analysis a quantitative guid, Chiester West Sussex, England

Cherkasov V. (1999). Problems in risk management activities, Refl-book, Moscow, Russia

Vasileva, S. (2010). Causes and effects: processes, aspects, risks. Methods of quality management, No.7, (07.2010) 60 (14-16), ISSN 0130-6898

*** (2009) http://www.iso.org - International Organization for Standardization, Talking "risk", Accessed on: 2011-06-26

*** (2011) http://www.quality.eup.ru - Risk management in the organization's management, Accessed on: 2011-06-18 